\title{
Projection of medical specialists in the Health Sector Mexico by 2030. A method to make projections about requirements and plan their training
}

\author{
Germán Fajardo-Dolci and Javier Santacruz-Varela² \\ ${ }^{1}$ Faculty of Medicine, Universidad Nacional Autónoma de México (UNAM); ${ }^{2}$ Department of Family Medicine, Postgraduate Studies Division, Faculty \\ of Medicine, UNAM, Ciudad de México, Mexico
}

\begin{abstract}
Objective: Carry out the projection of medical specialists in the Health Sector Mexico by 2030. Methods: A predictive approach was developed to project the number of medical specialists by 2030, according to a trend, a desired goal and two conventional scenarios of increased demand for health services. The methodology was developed based on the General Framework to Assess the Future Supply and Demand of Health Personnel, published in 2013 by the Organization for Economic Co-operation and Development (OECD), and a mathematical model and a software were designed to make projections about the number of specialists. Results: According to the trend, between 2013 and 2030, the number of specialists will be increased by 90,554 to 124,558 and the rate will be change of $77 / 100.000$ population to $91 / 100,000$ population. If is necessary to achieve a goal of 120/100,000, will be necessary to train 40,420 additional specialists to the trend number and if the demand for services increases $15 \%$ or $30 \%$, will require further training specialists 65,166 and 89,913 , respectively. Conclusions: Even with the trend increase, in the 2030 Mexico will not achieve the desired goal of 126/100,000 population, that the OECD countries had in 2011. The results of the projections made, can help to planning the training of specialists in the medium term.
\end{abstract}

KEY WORDS: Medical specialists planning. Training of health workers. Predictive methodologies.

\section{Introduction}

Ensuring opportune access to health services is one of the main goals of healthcare policies of the countries, and to achieve it, it is necessary having health personnel in sufficient numbers and type. One recurrent problem in health systems operation is the lack of medical personnel to provide services at the required places and moments, which is often due to failures in the definition of policies to plan healthcare personnel, or in their implementation. The consequences of inadequate medical personnel training are known: scarcity negatively affects medical care provision to people, and excessive job offer contributes to these health professionals' unemployment ${ }^{1,2}$.
The purpose of medical specialists planning is to generate sufficient supply to address the population demand of specialized medical services. Some countries have used predictive methods to plan the number of specialists required in the mid- and long-term, as well as to estimate the number that would be required to be trained according to different scenarios and working hypotheses ${ }^{3-11}$.

The planning of medical specialists, and of healthcare personnel in general, is a complex process that, in addition to requiring appropriate methods, has to take the policies and regulations that set the standards for training and professional practice into account ${ }^{12-14}$. In some countries, such as Canada, the training of medical specialists is consistent with
Gac Med Mex. 2017;153:804-819

Contents available at PubMed www.gacetamedicademexico.com 
undergraduate training in medical schools and with the number of general practitioners required by its model of care.

In addition to the definition of public policies, medical specialists planning requires efficacious mechanisms to sustainably and permanently apply them, such as committees and technical commissions. Although on Latin America these mechanisms are usually in charge of the ministries of health, in other countries, the participation of collegiate bodies, non-government organization and academic institutions contributes to significantly improve their efficacy and reliability, as it occurs in the United Kingdom with the General Medical Council and the Conference of Postgraduate Medical Deans, as well as in the USA with the Council on Graduate Medical Education ${ }^{15-18}$.

An autonomous, inter-institutional and multi-sectoral mechanism helps to overcome the old debate on whether it should adjust to the market forces or if, conversely, it should be only regulated by government guidelines. There is evidence that, if planning is performed according to the market forces, the private sector monopolizes specialists, reduces their availability in the public sector and increases the purchase of services beyond desirable; if, on the contrary, it is carried out only based on government needs, there may be scarcity of specialists in the private sector and costs of care increase in such sector ${ }^{19}$.

Planning is not restricted to define how many and what kind of specialists should be trained, but is should also include the monitoring of training quality and supervision of the sites where the specialization programs are carried out, in order to verify they have an appropriate structure, qualified teaching personnel, sufficient patient flow, and that they are credited as centers of excellence. In some countries, medical residency programs are approved by specialized bodies, as it is the case in the USA of the Accreditation Council for Graduate Medical Education ${ }^{20}$.

In Mexico, the training of specialists by means of medical residency programs goes back to several decades ago and, initially, the National Autonomous University of Mexico was the only institution that academically recognized them. Currently, several universities recognize the specialization programs and there is a plurality of places where they are imparted, and watching for training to be similar is therefore required in order to avoid asymmetries that later might affect professional performance and the quality of services ${ }^{21}$. Residency posts' planning and National Exam for Medical Residency Aspirants (ENARM - Examen
Nacional para Aspirantes a las Residencias Médicas) administration are the responsibility, since 1983, of the Inter-institutional Commission for the Training of Human Resources in Health (CIFRHS - Comisión Interinstitucional para la Formación de Recursos Humanos en Salud) $)^{22,23}$. This commission focuses on administering the referred exam, but its capability is limited for planning, since it lacks normative faculties or resources to do it, in spite of having a Committee for the Study of the Needs in the Training of Human Resources for Health.

One limitation for the planning of medical specialists in Mexico is that their real number is not known, since there are varying figures according to the consulted source. The General Directorate of Statistical Information (DGIS - Dirección General de Información Estadística) of the Ministry of Health published in their 2010 Statistical Information Bulletin that, for that year, the health public sector had 79,055 specialist posts, but in another communication, the same office refers that, when private sector specialists are included, the number reaches to up to $140,000^{24}$. In turn, the Organization for Economic Cooperation and Development (OECD) refers that, in 2011, the rate of medical specialists in Mexico was $1.26 / 1000$ population, which is a figure lower than the average in countries that belong to that organization and that on that year was $1.78 / 1000$ population, as shown in figure 1 , which includes other countries for comparison purposes ${ }^{25}$. OECD-referred Mexican rate should be taken with caution, since if calculated only with public sector posts, it is drastically reduced to $0.8 / 1000$.

Official data published by DGIS in 2012 refer that total physician posts in the public sector were 143,721 , out of which 84,796 corresponded to specialists and the remaining 58,925 to primary care doctors $(14,388$ family doctors and 44,537 general practitioners). However, the figure of specialist posts has to be adjusted, since it includes odontologists, and without them the number is reduced to 75,508 . If to the latter figure the 14,388 family physician posts are added, assuming all of them were occupied by specialists in that field, total number of posts for specialists in the public sector would be 89,977 , which, divided by the $117,053,750$ population estimated by the National Population Council for that same year, equals to a rate close to $0.8 / 1000$, which is much lower than the $1.26 / 1000$ rate referred by the OECD for Mexico in 2011. It should be clarified that the figures published by DGIS refer to the number of posts and not to medical specialists, and the number of them who are hired at the public 


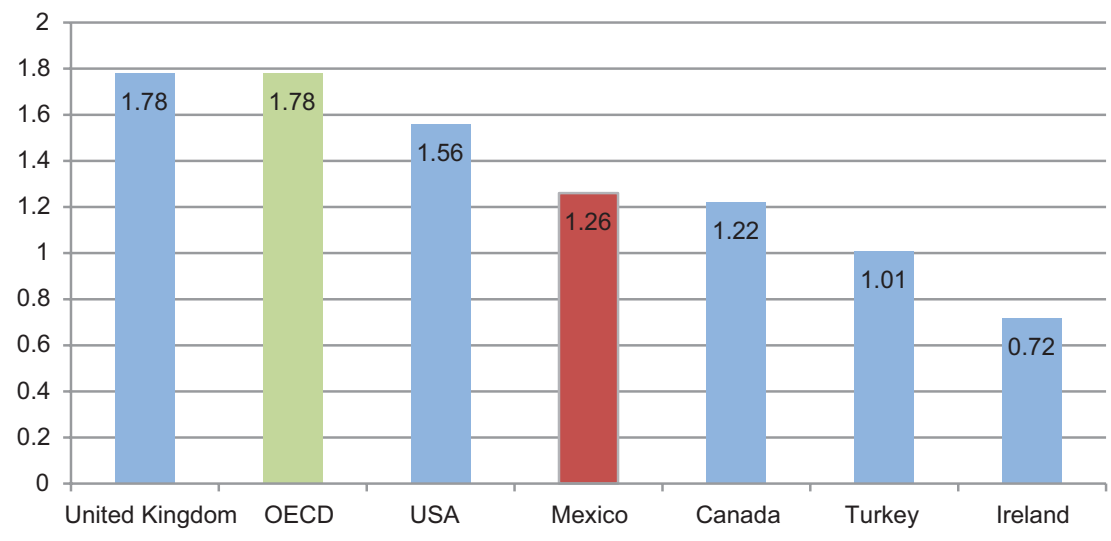

Figure 1. Rate of specialists per 1000 population, in 2010, in selected countries ${ }^{25}$.

sector must therefore be lower that the number of posts, since some of them work in more than one public institution.

In Mexico, specialist posts in the public sector are almost double than those of generalists (family and general doctors), and the difference is even greater if they are only compared with those of family medicine specialists (5:1 ratio). This imbalance overloads primary care consultation and reduces its resolving capability, thus increasing patient reference to hospitals and saturating their services. Imbalance between specialists and generalists is common to several countries such as the USA, Slovakia and Poland ${ }^{26}$. However, in Canada, France, Australia and Portugal there is higher balance between both, as shown in figure 2 .

Deficit of specialists in general, and of some in particular, has aggravated in the Mexican health sector, and it is critical in some specialties where patients with chronic and degenerative pathologies are attended to, including nephrology, oncology, pulmonology, urology, cardiology, geriatrics and psychiatry, where the demand of services has increased.

To address these public health challenges, reliable estimations of specialists in the mid- and long term have to be made, by using suitable projection methods, which differentiate from each other by their type of approach ${ }^{27}$. Depending on their approach, these methods can be classified in four types: supply-based, demand-based, necessity-based and benchmarking-based ${ }^{28}$ :

- Supply-based: they estimate the number of specialists required to care for the population, and use as key data the rate of specialist in a yearbase. If that year the rate is considered to be sufficient, it is only projected to the goal-year to preserve it, but if it is lower, a number that allows achieving the desired rate is projected ${ }^{29}$.
- Demand-based: they try to satisfy the use of specialized services by the population, and use expert-defined consumption indicators, such as hospital discharge annual percentage or number of consultations per capita ${ }^{30}$. If the usage or demand meet the base-year indicators, these are projected to a target year, and the number of required specialists to attain them is defined.

- Necessity-based methods: they try to satisfy the service needs according to the risk of getting sick by using indicators defined in regulations or by experts. If base-year indicators are considered appropriate, they well be projected to a target year to preserve them. A substantial difference between this method and the latter is that if there is demand it doesn't mean that there is no necessity, and vice-versa.

- Benchmarking-based methods: these methods are based on a comparison of "good practices". A health model or system with a rate of specialists regarded as being ideal or desirable, which is defined as "reference system", is identified and tried to be replicated ${ }^{31}$. Its main limitation is that there are no identical contexts or health systems.

The described methods have limitations, and the selection of any of them is for each working group or country to be decided according to their reality and the goals that are pursued. The limitation of sufficient and reliable data on the defined variables is often an obstacle to the use of any of them. Some methods also include variables that depend on economic development, such as public health expenditure and the number of posts in the health system, the prediction of which is not always feasible. 
120.0

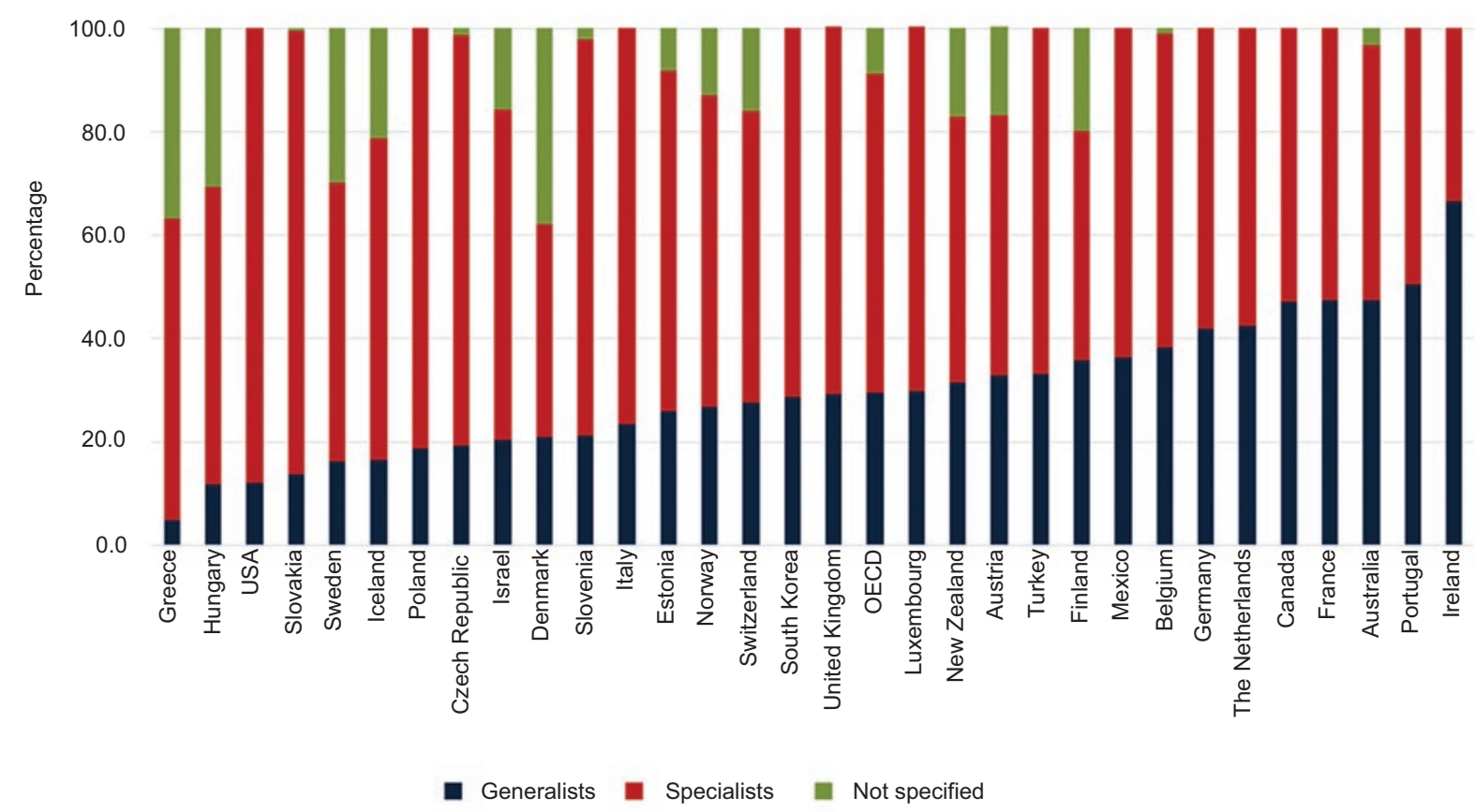

Figure 2. Generalist and specialist physicians in $2013^{26}$.

The development of a methodology to plan the number of specialists required by the Mexican Health System has been postponed for decades. So far, the number of residency posts to train medical specialists has been inertial, and each public health institution defines it according to its needs and budget, rather than by the use of a shared methodology. Neither has it been a common practice using long-term goals, predictive methodologies or scenarios for estimates to be established.

In view of the above, the National Academy of Medicine and the Postgraduate Studies Division of the UNAM Faculty of Medicine coordinated a project on Priorities in the Training of Medical Specialists, where personnel of both institutions and of three public health organizations (Ministry of Health, Mexican Institute of Social Security [IMSS - Instituto Mexicano del Seguro Social] and Institute of Social Security and Services of the State Workers [ISSSTE - Instituto de Seguridad y Servicios Soaciales de los Trabajadores del Estado] participated with the purpose to developed a methodology to establish the projection of the global number of specialists and of some specialists regarded as a priority in Mexico, with a time horizon towards 2030. The year 2012 was taken as the baseyear, as well the number of medical specialists reported by the General Directive of Information and
Statistics of the Ministry of Health and the National Population Council demographic estimates for the same year. Given that there are no reliable data about the number of medical specialists working at the private sector or who share their practice in both sectors, the study was restricted to project the number of medical specialists for the public health sector.

\section{Method}

A predictive methodology was developed to estimate the number of public health sector specialists for the period from 2013 to 2030, in the following three stages:

1. Frame of reference and working hypothesis selection.

2. Development of a mathematical model and a software to calculate estimates.

3. Validation of the mathematical formula and estimation of the number of specialists.

\section{First stage: frame of reference and working hypothesis selection}

The General Framework to Assess Future Supply and Demand of Health Workers, published in 2013 by the OECD based on the experience of 26 planning 


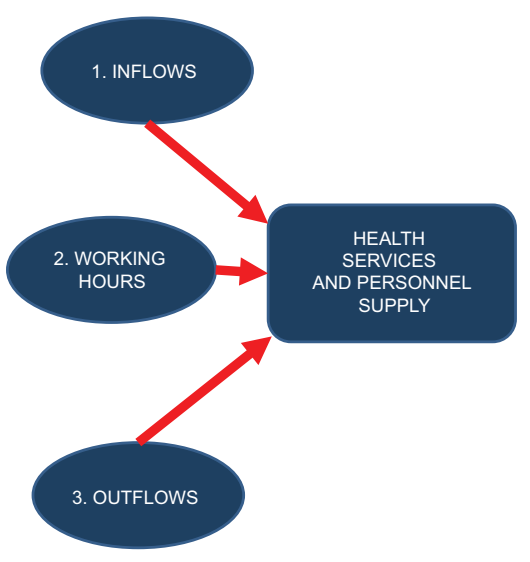

Figure 3. Framework to assess future health personnel supply and demand ${ }^{26}$.

models used in 18 countries, the components of which are shown in figure $3^{32}$, was selected and used as theoretical and conceptual framework.

The operative definition of the frame of reference components and their application to estimate the need of medical specialists was established by an interdisciplinary group where members of the National Academy of Medicine, of the Medical Specialties Academic Subcommittees of the UNAM Faculty of Medicine Postgraduate Division, as well as public health, mathematics and actuarial science professionals, participated. The operative definition are described next.

Supply: It is based on the assumption that medical specialists supply depends on three factors: public health inflows and outflows, and real working hours.

- Inflows: In the framework of this methodology, the inflow of specialists to the public health system for the period from 2013 to 2030 was considered to be dependent on three variables:

- Number of medical residents who will be admitted to the public health system for a medical specialty between 2013 and 2030 . This number was determined using two calculation methods: for the period from 2013 to 2016 , based on the number of residents admitted between 2000 and 2012 by means of the National Exam for Medical Residency Aspirants (ENARM), which was adjusted by subtracting the attrition rate during medical residency, estimated at $5 \%$. Medical residency average duration was set at 4 years, and residents admitted in 2009 will therefore join the health system as specialists in 2013, and those admitted in 2012 will do it in 2016.

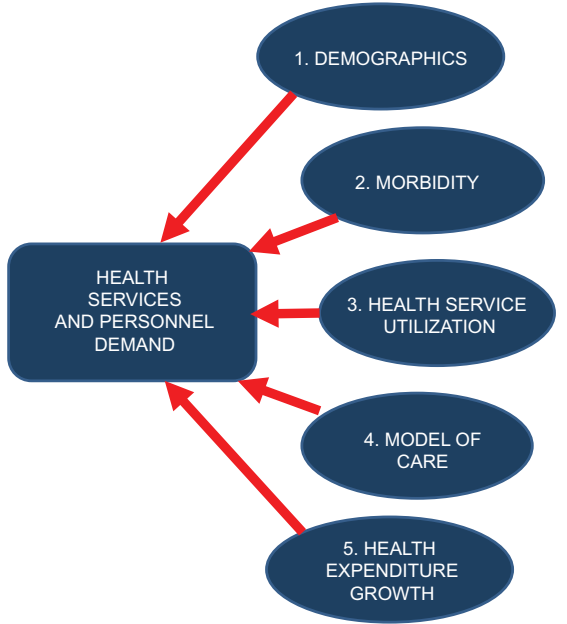

For the 2017 to 2030 period, the number of specialists was determined by lineal regression based on the number of medical residency posts offered from 2001 to 2012, which was also adjusting by subtracting $5 \%$ for attrition.

- Public health sector medical residency graduates retention rate. The incorporation of graduates to the Mexican public health system is not $100 \%$, since it depends on the number of newly created posts, from the posts left vacant by specialists who retire, and on the willingness of graduates to join the public sector. In this methodology, a retention rate of $60 \%$ was considered.

- Number of specialists working at the health sector in the immediate previous year. Even when properly speaking this is not an inflow, the number of immediately previous year specialists serves as a basis to estimate the number of specialists for the following year, which is added the number of graduating residents that is retained by the public sector.

- Outflows: In this methodology, the main outflow of health sector specialists was thought would be owing to physician retirements between 2013 and 2030. There are other possible outflows, such as voluntary resignation or migration, but were not considered due to the lack of data. Neither was mortality considered, since retirement in Mexico is at 65 years or less, and current life expectancy is higher than that age. Owing to the lack of information available from all public health institutions, the 
number of public sector retired specialists was calculated with IMSS retirees data provided by this institution's Human Resources Area. Based on this information, the number of the Ministry of Health and ISSSTE retirees was proportionally estimated, according to the number of specialists at each one of them in the public sector.

- Working hours: The 8-hour working day was used as a general average. For more accurate calculations on the real number of hours dedicated by specialists to medical care, it is necessary for this figure to be adjusted since, during the working day, specialists carry out other activities, such as education and research and, on the other hand, collective labor agreements in some institutions have managed to reduce real working hours. Conversely, an unknown percentage of specialists work longer than 8 hours, since they work in more than one institution.

Demand: The frame of reference used refers that the demand depends on five factors or variables: demographics, morbidity, health service utilization, model of care and health expenditure as a proportion of the gross domestic product (GDP). For the purposes of this methodology, the operative definition of these variable was the following:

- Demographics: population growth data estimated by the National Population Council (CONAPO Consejo Nacional de Población) for the 20132030 period were used.

- Morbidity: three morbidity or epidemiological variable hypothetical scenarios were considered. The first one is that it remains stable, and the other two pose a demand increase of $15 \%$ and $30 \%$, which will entail additional requirement of medical specialists due to morbidity changes.

- Health service utilization: it is mainly determined by the morbidity or epidemiological variable behavior, but there are other factors, such as the number of people covered by the People's Insurance, citizen's use of the health protection right, higher health education on the population and preventive medicine actions increase, which might increase health service utilization, which is already considered in both $15 \%$ and $30 \%$-increased demand scenarios.

- Model of care: based on the health system historical behavior and trends, the health service delivery model is expected to evolve in three axes. These three axes are: from disease-centered care to one with more emphasis on disease prevention; from predominance of medical specialists to one with more balance with primary care physicians; and from a system that emphasizes on hospital care to one that balances it with primary care. This foreseeable evolution of the health service delivery model will require a larger number of specialists for primary care.

- Health expenditure growth: health expenditure increase as a proportion of the GDP was not considered in this methodology, owing public finance uncertain behavior, international markets volatility and to income variations in the sale of oil. In spite of these uncertainties, health expenditure is expected to increase as a proportion of the GDP in the next decade and a half (2015 to 2030) (currently, it is around 6\%), and at the same time, to decrease private expenditure, which currently accounts for nearly $50 \%$ of total health expenditure.

With a rate of specialists of $120 / 100,000$ population, Mexican Health Sector will be able to satisfy the universal healthcare demand and to improve healthcare quality.

A group of professionals from public health institutions and academic organizations that participated in the project defined the achievement of a rate of $120 / 100,000$ as a goal for the Health Sector for the year 2030. This rate is similar to the rate in Canada in 2011, and was selected for the following two reasons:

- The first one, because with a 122/100,000 specialist-rate in 2011 (a figure lower than the OECD average for that year, which was 178/100,000), Canada has achieved the best global health and universal coverage indicators, as well as lower health expenditure per capita than other high income countries. Owing to this, it is foreseeable that this country will not considerably modify its rate of specialists by the year 2030 .

- The second one, because the Canadian Health System has achieved a balance between medical specialists and medical generalists (on that country, the latter are family physicians), which allows for it to have a health service delivery model based on primary care, which is consistent with the expected trend of the Health Service Delivery Model in Mexico.

\section{Second stage: development of a mathematical model}

To estimate the trend in the number of public sector specialists between 2013 and 2030, as well as the medical specialist gap or deficit between that number 
and the number required to achieve the goal of $120 / 100,000$ population by 2030 , the following formula was developed:

where:

$$
\begin{aligned}
B_{t} & =R_{t}-R_{t}^{\circ} \\
t & \in[m, n]
\end{aligned}
$$

$B_{t}$ : medical specialists gap per 100,000 population for year $t$ or for a given year.

$R_{t}^{\circ}$ : number of medical specialists according to a goal per 100,000 population, for year $t$.

$R_{t}$ : number of medical specialists per 100,000 population estimated for year $t$.

$m$ : year when the medical specialists planning process is initiated.

$n$ : year when the desired goal of medical specialists per 100,000 is expected to be reached.

Applying this formula, three possible results can be obtained: in the first one, there is no gap between the rate that is obtained by trend and the rate defined as the 2030 goal (the supply of specialists is equal to the demand); in the second, there is a positive gap, which means the rate trend is higher than the desired goal or rate (supply of specialists higher than the demand); and in the third one, there is a negative gap, which means that, by trend, the rate is lower than the desired goal (supply of specialists lower than the demand). These possibilities are described next:

- If $B_{t}$ is positive, then $R_{t}>R_{t}^{\circ}$, and hence the estimation will indicate that there is medical specialists surplus for year $t$.

- If $B_{t}$ is negative, then $R_{t}^{\circ}>R_{t}$ (or $R_{t}<R_{t}^{\circ}$ ), and hence the estimate will indicate that there's going to be medical specialists deficit for year $t$.

- If $B_{t}$ is 0 , then $R_{t}=R_{t}^{\circ}$, and hence the estimation will indicate that, for year $t$, the number of medical specialists is equal to the number required as desirable goal or rate.

The variables to calculate the inflow or admission of specialists into the health system, according to the frame of reference formulated by the OECD are:

$\rho_{\mathrm{t}-4}:$ Physicians admitted to train for the specialty on year $\mathrm{t}-4$.

$d$ : specialty attrition percentage.

$r$ : specialty graduates retention percentage.

$l_{t}$ : number of medical specialists reinstated in the public health sector.

$E_{m}$ : number of active medical specialists on year $m$. This information is known for the first year or baseyear. Since the formula is recursive, it is possible for the number of specialists for years $m+1$ until $n$ to be estimated.
The variable used to calculate specialists' outflow from the health system, according to the frame of reference formulated by the OECD, are:

$J_{t}$ : estimated number of medical specialists retiring on year $t$.

$M_{t}$ : estimated number of medical specialists dying on year $t$.

$S_{t}$ : estimated number of medical specialists retiring from the public sector on year $t$ for any reason other than retirement or death.

In this methodology, as well as in the developed formula, only the $J_{t}$ variable was considered.

Calculation of the gap between supply and demand, without variation in service demand.

In an ideal situation or favorable scenario where there was no increase in health service demand, the formula to estimate $B_{t}$ is the following:

$B_{t}=\left\{\begin{array}{c}0, t \in[m, m+3] \\ R_{t}-\frac{R_{n}^{o}(1+j)-R_{m+3}}{n-(m+3)} *(t-m-3)+R_{m+3}, t \in[m+4, n]\end{array}\right.$

It can also be expressed as:

$B_{t}=\left\{\begin{array}{c}0, t \in[m, m+3] \\ R_{t}-\frac{R_{n}^{o}(1+j)-R_{m+3}}{n-(m+3)} *(t-n)+R_{n}^{o}(1+j), t \in[m+4, n]\end{array}\right.$

where $J$ is the increase in medical specialist service demand, expressed as a percentage.

Calculation of the gap in absolute numbers

$B_{t}^{N}$ refers to the number of specialists per 100,000 population in excess or missing to address the demand for health service supply, and it is represented in absolute numbers. To obtain this number, the following formula is applied:

$$
B_{t}^{N}=\frac{B_{t}^{*} P_{t}}{100,000}
$$

\section{Third stage: formula validation and number of specialists estimation}

In order for the described mathematical formula to be validated, four estimations of the number of specialists were carried out: the first one, to estimate the trend in specialists increase between 2013 and 2030; the second one, to estimate the increase according to a 120/100,000 goal for the year 2030 under the assumption that heath service demand is not modified $(0 \%)$; and the next two, to estimate the increase of specialists required to reach the goal set and to address two hypothetical $15 \%$ and $30 \%$ gradual increases in service demand between 2013 and 2030. The 
Table 1. Trend-wise estimation of specialists from 2013 to 2030

\begin{tabular}{|c|c|c|c|c|c|c|}
\hline Year & $\begin{array}{l}\text { No. of specialists } \\
\text { according to the } \\
\text { trend* }\end{array}$ & Population ${ }^{\dagger}$ & $\begin{array}{c}\text { Rate of specialists per } \\
100,000 \text { according to } \\
\text { the trend }{ }^{\ddagger}\end{array}$ & $\begin{array}{c}\text { Estimated no. of physicians } \\
\text { who started their residency } \\
\text { on year } t-4^{\S}\end{array}$ & $\begin{array}{l}\text { No. of residents } \\
\text { retained in the public } \\
\text { sector }\end{array}$ & $\begin{array}{l}\text { Retirements in the } \\
\text { public sector }\end{array}$ \\
\hline 3009 & 90,554 & $118,395,054$ & 76 & 6,291 & 3,586 & 3009 \\
\hline 3093 & 91,094 & $119,713,203$ & 76 & 6,372 & 3,632 & 3093 \\
\hline 3510 & 91,275 & $121,005,815$ & 75 & 6,476 & 3,691 & 3510 \\
\hline 3923 & 91,322 & $122,273,473$ & 75 & 6,964 & 3,969 & 3923 \\
\hline 3861 & 91,416 & $123,518,270$ & 74 & 6,939 & 3,955 & 3861 \\
\hline 3615 & 92,123 & $124,737,789$ & 74 & 7,583 & 4,322 & 3615 \\
\hline 3119 & 93,490 & $125,929,439$ & 74 & 7,870 & 4,486 & 3119 \\
\hline 2808 & 95,332 & $127,091,642$ & 75 & 8,158 & 4,650 & 2808 \\
\hline 2561 & 97,586 & $128,230,519$ & 76 & 8,446 & 4,814 & 2561 \\
\hline 2576 & 99,988 & $129,351,846$ & 77 & 8,734 & 4,978 & 2576 \\
\hline 2591 & 102,539 & $130,451,691$ & 79 & 9,022 & 5,142 & 2591 \\
\hline 2607 & 105,239 & $131,529,468$ & 80 & 9,310 & 5,306 & 2607 \\
\hline 2622 & 108,087 & $132,584,053$ & 82 & 9,597 & 5,470 & 2622 \\
\hline 2638 & 111,084 & $133,614,190$ & 83 & 9,885 & 5,635 & 2638 \\
\hline 2653 & 114,229 & $134,619,411$ & 85 & 10,173 & 5,799 & 2653 \\
\hline 2668 & 117,524 & $135,599,641$ & 87 & 10,461 & 5,963 & 2668 \\
\hline 2684 & 120,967 & $136,554,494$ & 89 & 10,749 & 6,127 & 2684 \\
\hline 2699 & 124,558 & $137,481,336$ & 91 & 11,036 & 6,291 & 2699 \\
\hline
\end{tabular}

*Supply of specialists for the public sector according to the expected trend.

†Figures projected by CONAPO.

¥Obtained by dividing the estimated number of specialists by the population projected by CONAPO.

${ }^{\S}$ Corresponds to medical residency posts offered through ENARM.

"Calculated with an average retention rate of $60 \%$.

${ }^{* *}$ Calculated for the entire sector, according to figures provided by IMSS.

results of the three estimations were contrasted with those of the first one to determine the magnitude of the gaps. The calculations were carried out in an automatized with an ad hoc in-house-developed software.

The above-described estimations were performed for total public sector specialists and for 10 selected specialties. Only total estimates are presented in this publication.

\section{Results}

From the baseline data of 8,977 medical specialists and a rate of $77 / 100,000$ population in 2012, projection from 2013 to 20130 by inertia or trend was estimated. The results are shown in table 1.

According to the expected trend, the number of specialists will increase from 89,977 in 2012 to 124,558 in 2030 , and the rate is going to increase from
$77 / 100,000$ to $91 / 100,000$ throughout that period. In spite of this increase, the rate of specialists in the Mexican public sector in 2030 will continue to be lower than the average rate the OECD countries had in 2010 , which was $178 / 100,000$. Population annual projections published by CONAPO, as well as the number of residents that will start a medical specialty, the number of retained graduates and the number of public health sector retirees are also presented in table 1. The increase by trend or inertia of the number of specialists in the public sector from 2013 to 2030 is shown in table 4.

Achieving a goal of 120 medical specialists per 100,000 population is going to require a larger number of specialists than that of increase by trend. The results are shown in table 2.

Reaching the $120 / 100,000$ population goal by 2030 will require for 164,978 medical specialists to be available. Then these results are compared with those 
Table 2. Estimation of specialists for a $120 / 100,000$ goal

\begin{tabular}{|c|c|c|c|c|c|c|}
\hline Year & $\begin{array}{l}\text { No. of specialists } \\
\text { according to the } \\
\text { trend }\end{array}$ & $\begin{array}{l}\text { Rate of specialists } \\
\text { per } 100,000 \text { in } 2030 \text {, } \\
\text { according to the trend }\end{array}$ & $\begin{array}{c}\text { Specialists required to } \\
\text { reach the } 120 / 100,000 \\
\text { goal by } 2030\end{array}$ & $\begin{array}{c}\text { Rate of specialists per } \\
100,000 \text { required to } \\
\text { reach the } 120 / 100,000 \\
\text { goal by } 2030\end{array}$ & $\begin{array}{l}\text { Gap of } \\
\text { specialists } \\
\text { in rates }\end{array}$ & $\begin{array}{c}\text { Gap of specialists } \\
\text { in absolute } \\
\text { numbers }\end{array}$ \\
\hline 2013 & 90,554 & 77 & 90,554 & 77 & 0 & 0 \\
\hline 2014 & 91,094 & 76 & 94,627 & 79 & -3 & $-3,533$ \\
\hline 2015 & 91,275 & 75 & 98,746 & 82 & -6 & $-7,471$ \\
\hline 2016 & 91,322 & 75 & 102,910 & 84 & -9 & $-11,588$ \\
\hline 2017 & 91,416 & 74 & 107,120 & 87 & -13 & $-15,704$ \\
\hline 2018 & 92,123 & 74 & 111,370 & 89 & -15 & $-19,247$ \\
\hline 2019 & 93,490 & 74 & 115,658 & 92 & -18 & $-22,167$ \\
\hline 2020 & 95,332 & 75 & 119,978 & 94 & -19 & $-24,646$ \\
\hline 2021 & 97,586 & 76 & 124,336 & 97 & -21 & $-26,750$ \\
\hline 2022 & 99,988 & 77 & 128,734 & 100 & -22 & $-28,746$ \\
\hline 2023 & 102,539 & 79 & 133,168 & 102 & -23 & $-30,629$ \\
\hline 2024 & 105,239 & 80 & 137,635 & 105 & -25 & $-32,396$ \\
\hline 2025 & 108,087 & 82 & 142,132 & 107 & -26 & $-34,045$ \\
\hline 2026 & 111,084 & 83 & 146,656 & 110 & -27 & $-35,573$ \\
\hline 2027 & 114,229 & 85 & 151,206 & 112 & -27 & $-36,976$ \\
\hline 2028 & 117,524 & 87 & 155,778 & 115 & -28 & $-38,254$ \\
\hline 2029 & 120,967 & 89 & 160,370 & 117 & -29 & $-39,403$ \\
\hline 2030 & 124,558 & 91 & 164,978 & 120 & -29 & $-40,420$ \\
\hline
\end{tabular}

obtained by trend-wise increase, a negative gap of 40,420 specialists is found, which equals to a $35.5 \%$ or 29/100,000 deficit, as shown in figure 5 .

The results are shown in table 3 . With a $15 \%$ demand increase, 189,724 medical specialists would be required in the year 2030, and thus the gap or deficit with regard to the 124,558 expected by the trend is 65,166 specialists, which equals to a deficit of $52.3 \%$ or $47 / 100,000$, as shown in figure 6 .

The results are shown in table 4 . With a $30 \%$ increase in health service demand, the required physicians to be able to address it by 2030 add up to 214,471 specialists, and the gap with regard to the trend-estimated number of medical specialists would therefore be 89,913 medical specialists, which corresponds to a $72.2 \%$ deficit, or $65 / 100,000$ if expressed as a rate, as shown in figure 7 .

\section{Discussion}

Defining the number of the different categories of personnel required by a health system in the long term is not an easy task, owing to possible changes that can occur in the epidemiological and demographic profiles, in the demand of service, in the health service supply model, in the capacity of teaching institutions to train personnel and other variables that influence on its planning. In addition, there are economic and social factors that are difficult to control in the long term, and numerical projections of personnel must therefore be adjusted during the course of the time they are made for.

Education and health authorities often have to make decisions about the number and type of workers that have to be trained and hired, of the type of skills they have to possess and how they have to be distributed. Opportune and mid-term health personnel planning aids these decisions ${ }^{33}$.

Investigations on the number of physicians performed by international organizations reveal that the countries have wide variations in the rate of physicians per population ${ }^{34}$. A similar situation occurs with the rate of medical specialists, which confirms the 


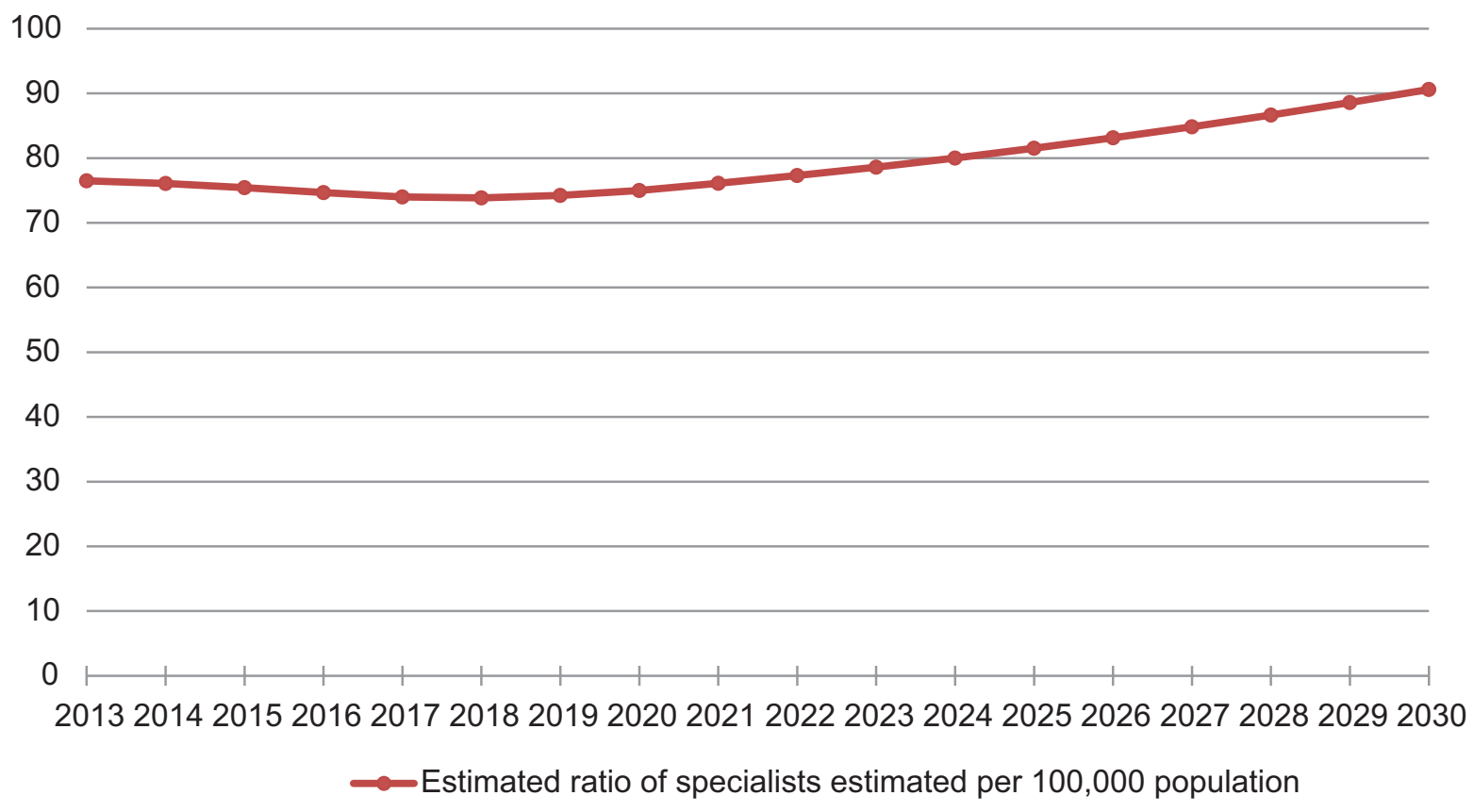

Figure 4. Estimation of medical specialists increase by trend from 2013 to 2030. Rate per 100,000 population.

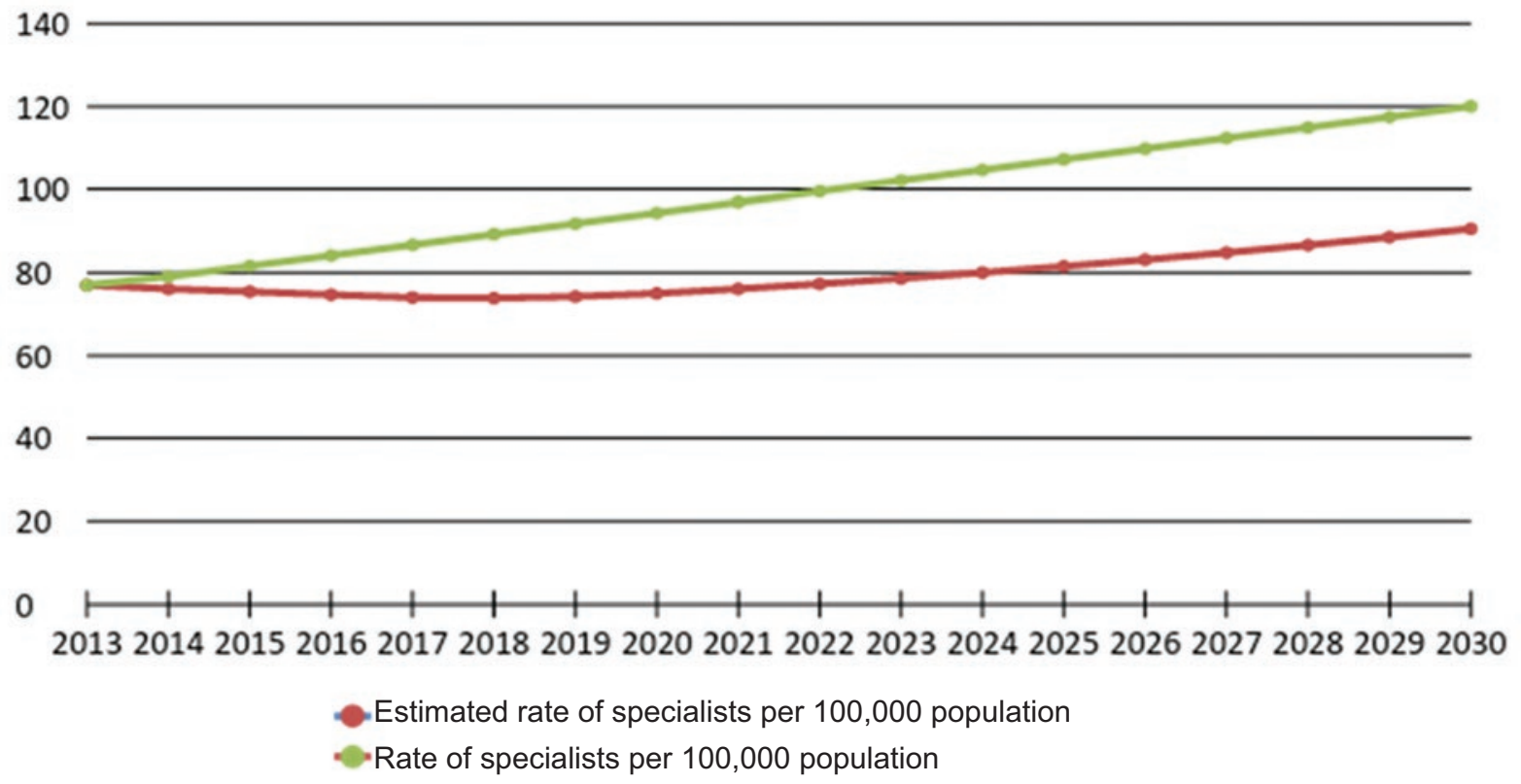

Figure 5. Gap of specialists in a situation of $0 \%$ demand increase.

diversity of criteria used to train them and that there is no reference parameter.

In migration-affected Asian and European countries, this phenomenon is considered to be an important factor that influences on specialized medical personnel planning since, depending on migratory flow direction, in some cases it will produce a shortage and in others oversupply of this personnel ${ }^{35,36}$. Shortage is not desirable because it hinders access to health services, and this affects mainly groups with the lowest economic capacity. In contrast, oversupply produces an unfortunate loss of human capital and causes under- or unemployment.

The main purpose of health personnel planning is to achieve an appropriate balance between supply and offer of its different categories. One of these categories where carrying out a careful planning process is necessary is that of medical specialists, due to the healthcare 
Gaceta Médica de México. 2017;153

Table 3. Specialists by trend and those required according to a $15 \%$ demand increase

\begin{tabular}{|c|c|c|c|c|c|c|}
\hline Year & $\begin{array}{l}\text { No. of specialists } \\
\text { according to the } \\
\text { trend }\end{array}$ & $\begin{array}{c}\text { Rate of specialists } \\
\text { per } 100,000 \text { in } 2030, \\
\text { according to the } \\
\text { trend }\end{array}$ & $\begin{array}{c}\text { Specialists required to } \\
\text { address a } 15 \% \text { demand } \\
\text { increase }\end{array}$ & $\begin{array}{l}\text { Rate of specialists per } \\
100,000 \text { according to a } \\
15 \% \text { demand increase }\end{array}$ & $\begin{array}{l}\text { Gap of } \\
\text { specialists in } \\
\text { rates }\end{array}$ & $\begin{array}{c}\text { Gap of specialists } \\
\text { in absolute } \\
\text { numbers }\end{array}$ \\
\hline 2013 & 90,554 & 77 & 90,554 & 77 & 0 & 0 \\
\hline 2014 & 91,094 & 76 & 95,894 & 80 & -4 & $-4,801$ \\
\hline 2015 & 91,275 & 75 & 101,308 & 84 & -8 & $-10,033$ \\
\hline 2016 & 91,322 & 75 & 106,794 & 87 & -13 & $-15,472$ \\
\hline 2017 & 91,416 & 74 & 112,351 & 91 & -17 & $-20,935$ \\
\hline 2018 & 92,123 & 74 & 117,974 & 95 & -21 & $-25,851$ \\
\hline 2019 & 93,490 & 74 & 123,658 & 98 & -24 & $-30,168$ \\
\hline 2020 & 95,332 & 75 & 129,398 & 102 & -27 & $-34,066$ \\
\hline 2021 & 97,586 & 76 & 135,197 & 105 & -29 & $-37,612$ \\
\hline 2022 & 99,988 & 77 & 141,060 & 109 & -32 & $-41,072$ \\
\hline 2023 & 102,539 & 79 & 146,980 & 113 & -34 & $-44,441$ \\
\hline 2024 & 105,239 & 80 & 152,954 & 116 & -36 & $-47,715$ \\
\hline 2025 & 108,087 & 82 & 158,978 & 120 & -38 & $-50,891$ \\
\hline 2026 & 111,084 & 83 & 165,048 & 124 & -40 & $-53,964$ \\
\hline 2027 & 114,229 & 85 & 171,161 & 127 & -42 & $-56,932$ \\
\hline 2028 & 117,524 & 87 & 177,314 & 131 & -44 & $-59,790$ \\
\hline 2029 & 120,967 & 89 & 183,504 & 134 & -46 & $-62,537$ \\
\hline 2030 & 124,558 & 91 & 189,724 & 138 & -47 & $-65,166$ \\
\hline
\end{tabular}

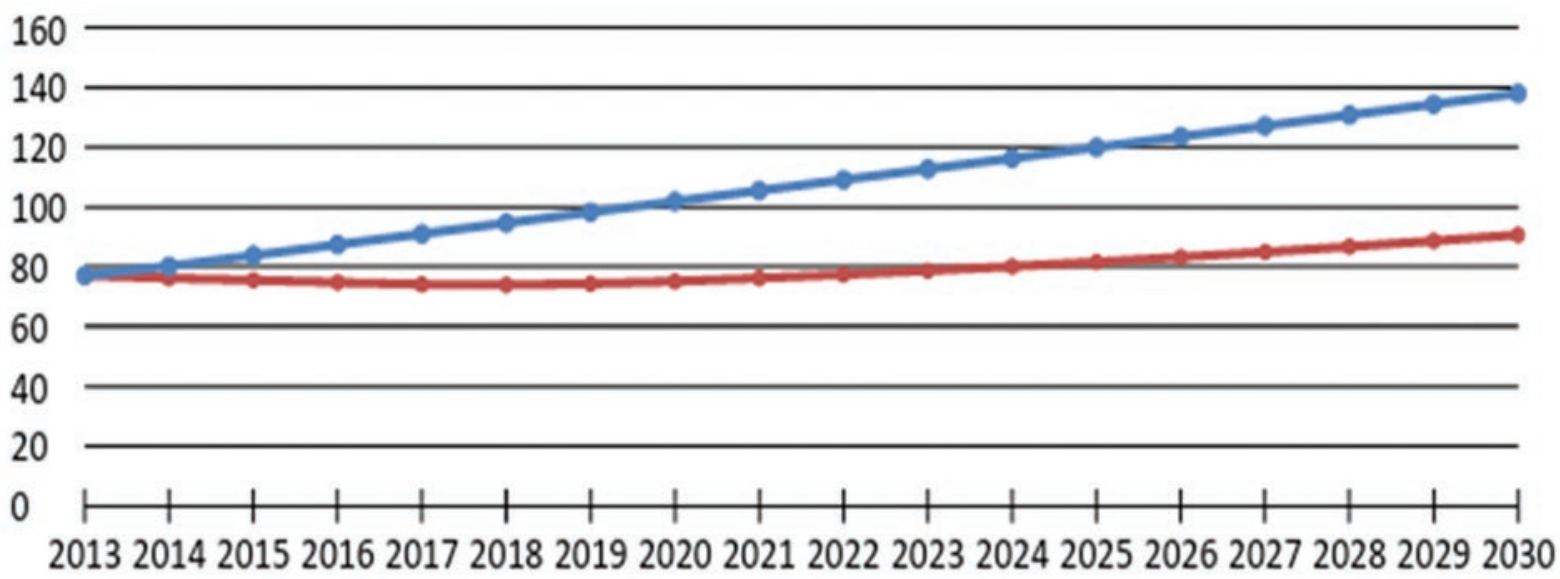

Estimated rate of specialists per 100,000 population

Goal of specialists per 100,000 population

Figure 6. Gap of specialists in a situation of $15 \%$ demand increase.

infrastructure resources or "clinical fields" that are required for their training and the costs it implies, and because it is a prolonged educational process that in some specialties can be as long as 5 years or longer. 
Table 4. Specialists by trend and those required according to a $30 \%$ demand increase

\begin{tabular}{|c|c|c|c|c|c|c|}
\hline Year & $\begin{array}{l}\text { No. of specialists } \\
\text { according to the trend }\end{array}$ & $\begin{array}{l}\text { Rate of specialists } \\
\text { per } 100,000 \text { in } 2030 \text {, } \\
\text { according to the trend }\end{array}$ & $\begin{array}{c}\text { Specialists required } \\
\text { to address a } 30 \% \\
\text { demand increase }\end{array}$ & $\begin{array}{l}\text { Rate of specialists per } \\
100,000 \text { according to a } \\
30 \% \text { demand increase }\end{array}$ & $\begin{array}{l}\text { Gap of } \\
\text { specialists } \\
\text { in rates }\end{array}$ & $\begin{array}{c}\text { Gap of specialists } \\
\text { in absolute } \\
\text { numbers }\end{array}$ \\
\hline 2013 & 90,554 & 77 & 90,554 & 77 & 0 & 0 \\
\hline 2014 & 91,094 & 76 & 97,162 & 81 & -5 & $-6,068$ \\
\hline 2015 & 91,275 & 75 & 103,871 & 86 & -10 & $-12,596$ \\
\hline 2016 & 91,322 & 75 & 110,678 & 91 & -16 & $-19,356$ \\
\hline 2017 & 91,416 & 74 & 117,582 & 95 & -21 & $-26,166$ \\
\hline 2018 & 92,123 & 74 & 124,578 & 100 & -26 & $-32,454$ \\
\hline 2019 & 93,490 & 74 & 131,658 & 105 & -30 & $-38,168$ \\
\hline 2020 & 95,332 & 75 & 138,818 & 109 & -34 & $-43,486$ \\
\hline 2021 & 97,586 & 76 & 146,059 & 114 & -38 & $-48,474$ \\
\hline 2022 & 99,988 & 77 & 153,387 & 119 & -41 & $-53,399$ \\
\hline 2023 & 102,539 & 79 & 160,793 & 123 & -45 & $-58,254$ \\
\hline 2024 & 105,239 & 80 & 168,273 & 128 & -48 & $-63,035$ \\
\hline 2025 & 108,087 & 82 & 175,824 & 133 & -51 & $-67,737$ \\
\hline 2026 & 111,084 & 83 & 183,440 & 137 & -54 & $-72,356$ \\
\hline 2027 & 114,229 & 85 & 191,116 & 142 & -57 & $-76,887$ \\
\hline 2028 & 117,524 & 87 & 198,850 & 147 & -60 & $-81,327$ \\
\hline 2029 & 120,967 & 89 & 206,638 & 151 & -63 & $-85,671$ \\
\hline 2030 & 124,558 & 91 & 214,471 & 156 & -65 & $-89,913$ \\
\hline
\end{tabular}

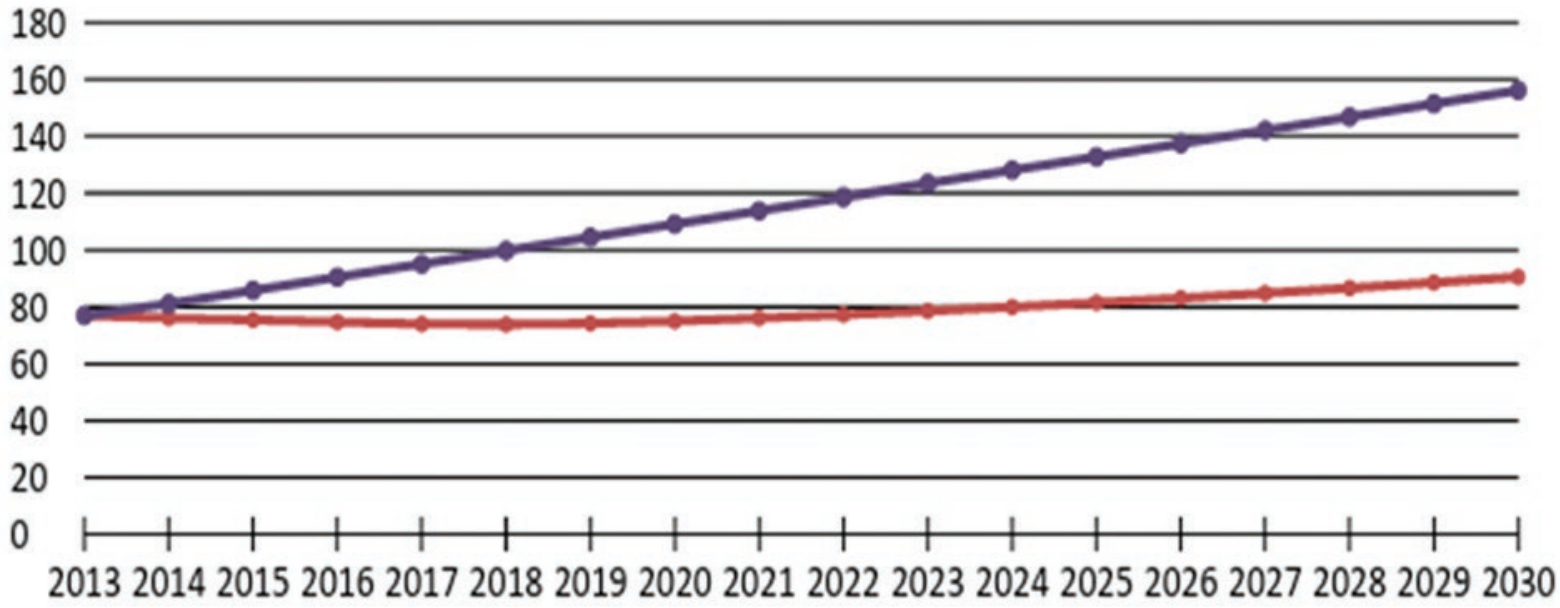

Estimated rate of specialists per 100,000 population

Goal of specialists per 100,000 population

Figure 7. Gap of specialists in a situation of $30 \%$ demand increase.

The presented planning methodology was developed within the framework of the project Priorities in the Training of Medical Specialists, carried out jointly by the National Academy of Medicine and the Postgraduate Division of the UNAM Faculty of Medicine. This methodology took 2012 as the base year and 
enabled the projection of the number of Mexican Public Health System medical specialists for 2030 by trend or by inertia, based on variables affecting specialists' supply and demand, such as the annual number of posts offered by the health sector between 2001 and 2011, physicians' dropout during residency and their hiring in the public sector at residency conclusion. In addition, the number of specialists that will retire in the public sector between 2013 and 2030 were also considered, as well as CONAPO population projections for the same time period. Furthermore, mathematical correlation of these variables enabled estimating the number of specialists that will be required in case the country decides to reach a goal other than that which will be achieved by trend in 20130, as well as the gap between this goal and the number of specialists required to address two hypothetical scenarios of health service demand increase.

The described methodology was based on the Framework to Assess Health Personnel Future Supply and Demand, formulated and published by and OECD working group, which includes a supply and demand set of factors or variables that influence on health personnel planning. The authors of that framework refer that the inclusion of all variables constitutes a real challenge, since the required data are not always available or reliable.

In the present study, there were difficulties to obtain information on some variables, such as real working hours, the number of specialists that will retire in all public health institutions, the specialists' retention rate and the proportion of specialists who voluntarily resign. On the side of demand, problems were larger because there are no estimates on the proportion of GDP that will be assigned for health public expenditure for the next years, on the burden of disease, globally and for different types of conditions, on the evolution of the rates of health service use by age and gender, as well as on the evolution the health service supply model will have to undergo in order to address these challenges. We tried to compensate for such limitations by means of the opinion of a group of experts, and in future studies these shortfalls might be complemented or even replaced as data become available and these have sufficient disaggregation level as to perform more accurate calculations and define the necessities for each specialty, each State, each region and each institution, as it has been done in similar studies ${ }^{37}$.
It should be mentioned that, although some qualify expert opinions as a weakness, in medical personnel planning, health personnel and hospital managers interview is regarded as a valid resource, since it allows collecting useful information of professionals that are in contact with the population and it health necessities ${ }^{38}$.

The lack of information found should be regarded as a secondary outcome of this study, but a very important one since it directly points at where data systemization efforts should be directed in order for new studies on medical specialists' availability to be conducted in the future and know the shortage or oversupply in different categories, which with no doubt represents quite a challenge for health personnel planners in the country.

This study is the first one to be developed in the international setting explicitly using the frame of reference proposed by the OECD working group and its variables. The employed methodology, as well as its outcomes, were discussed with one of the members of that working group. However, it should be mentioned that this methodology has some similarities with those that have been used in the past by other working groups to perform estimations of specialists in Brazil, Chile and Spain, as well as with those that have been employed to make projections of some specific medical specialties such as urology, rheumatology, angiology and pulmonology ${ }^{39}$.

The frame of reference designed by the OECD group does not include any formula or model that mathematically correlates the variables included in said frame. Owing to this, as part of the methodological development, a mathematical formula was designed in order to the number of specialists by trend, where variables influencing on their supply and demand are interrelated. This formula was validated by making automatized calculations of specialists according to the expected trend, a desired goal and different demand increase proposed scenarios, supported by a software ad hoc developed for this purpose. In this report, the elements of the formula have been described sufficiently detailed as to understand the nature of the presented results and the mathematical logic that enabled obtaining them.

On the other hand, the software designed for this study, which considered the medical specialists' supply and demand variables correlation, has the advantage that it allows the performance of new estimations only by including values other than the used variables, such as the number of retirees, the number of posts 
offered during medical residency, the rate of attrition during residency, the rate of graduate retention in the public sector and different percentages of health service demand increase.

The results obtained aided by the software allow observing that the trend-wise increase of medical specialists in the year 2030 will reach to $91 / 100,000$ population, and that the rate of $77 / 100,000$ population observed in 2012 will therefore not be substantially modified. Although this an overall figure of medical specialists and does not refer to specific specialties, beyond the fact that the OECD countries average rate, which in 2013 was 178/100,000, will not be reached, this should draw the attention of those who are responsible for the planning of medical specialists, since they will have to decide which is the required rate and in how much time is it desired to be reached since, by not doing it, it is predictable for the shortage to become more critical in some specialties and services that right now are already saturated.

On the other hand, the estimation of specialists according the working hypothesis agreed buy a group of experts, which proposed a desirable goal or rate of 120 specialists per 100,000 population in 2030 , reveals a gap between the rate by trend and the goal of nearly $30 \%$, which equates to a deficit of 40,420 medical specialists, as long as service demand does not increase, since if it increases by $15 \%$, the deficit reaches to 65,166 specialists, and if it increases by $30 \%$, the deficit is even greater, and would add up to 89,913 specialists.

To the problem of specialists' deficit, the issue of their uneven distribution across the country would have to be added, which requires other type of strategies to prevent their concentration in some regions and cities, in order to achieve a distribution that contributes to health equity, an ideal situation that is periodically insisted on but that has not been achieved in spite of the strategies used by public health institutions, which is why there are areas of the country that persist with chronic specialists' deficits.

The results obtained with exercises performed in hypothetical situations and scenarios related to an increase in heath service demand allow anticipating the magnitude of specialists that need to be trained and hired in case that, as it is foreseeable, health service demand increases in the future owing to life expectancy increase, to early appearance of chronic conditions and comorbidity. It should be noted that the calculations were only made for the public sector, and although they do not include the private sector needs, they have the advantage that they refer to a market regulated by public health institutions themselves, which can reach consensuses on the direction the planning of specialists should take in this country. However, this does not mean that comprehensive planning leaves the private sector needs aside, especially in a country with mixed economy where private health expenditure is very close to $50 \%$ of total health expenditure.

On the other hand, it should be emphasized that the problems of medical specialists" training through medical residency programs only refer to a stage of transition between the moment when physicians graduate from school and join the working market as medical specialists, either in the public or private sector, or on both. This indicates the necessity to review the medical training process as a whole or comprehensively, as a continuum, in order for educational offer to be interrelated with the working market and the market of health service supply, such as the World Health Organization has proposed, with the purpose to achieve a balance between training, the job and professional service ${ }^{40}$.

In addition to their application in medicine, predictive models, as the one here described, are used in many fields, such as administration and economics, with the purpose to calculate, based on a historical series of data, the course a phenomenon under study will take in the future. In the field of health, they have been used to predict the possibility that patients with particular symptoms develop a complication, or that individuals with certain risk factors develop a particular disease ${ }^{41,42}$.

The obtained results show the magnitude of the gaps according to an ideal scenario and two hypothetical scenarios of increased health service demand. However, they should be taken with caution, since some variables are subject to unforeseen modifications and not attributable to the methodology, which would modify the calculations made and different results would be obtained. However, this doesn't belittle the intrinsic predictive value or usefulness of predictive methodologies, which have helped for medical specialists' deficits or surpluses to be estimated, which over time were verified to be true and that could have been prevented or avoided by means of planning ${ }^{43}$.

Finally, the results only show scenarios about the number of medical specialists estimated with a limited set of variables, which can be improved inasmuch as there is information available on other variables 
proposed by the used model and that could not be obtained, as well as on new emerging variables that demonstrate an impact on medical specialists' future supply and demand.

\section{Funding}

Study developed with financial support of Consejo Nacional de Ciencia y Tecnología (CONACYT).

\section{Conflicts of interests}

The authors declare not having any conflicts of interests. The concepts and comments expressed in the present article are the sole responsibility of the authors and do not correspond to an official position of the institution they work in or of the funding organization.

\section{References}

1. Zurn P, Dal Poz MR, Stilwell B, et al. Imbalance in the health workforce. Hum Resour Health. 2004;2(1):13. (Consultado el 21 de enero de 2013.) Disponible en: http://www.human-resources-health.com/content/2/1/13.

2. Dussault G, Franceschini MC. Not enough there, too many here: understanding geographical imbalances in the distribution of the health workforce. Hum Resour Health. 2006;4:12. (Consultado el 4 de enero de 2012.) Disponible en: http://www.human-resources-health.com/content/4/1/12

3. The Cecil G. Sheps Health Center for Health Services Research. Developing an open-source model for predicting physician shortages in the United States. UNC Chapel Hill, in partnership with the North Carolina Medical Society Foundation, with support from the Physicians Foundation. August 2012. (Consultado el 8 de enero de 2013.). Disponible en: http://www.shepscenter.unc.edu/workforce_product/developing-open-source-model-projecting-physician-shortages-united-states/.

4. VanGreuningen M, Batenburg RS, Van der Velden LF. Ten years of health workforce planning in the Netherlands: a tentative evaluation of GP planning as an example. Hum Resour Health. 2012;10:21. (Consultado el 10 de enero de 2012.) Disponible en: http://www.human-resources-health.com/content/10/1/21

5. Health Workforce. An Australian Government Initiative. Health workforce 2025. Medical specialties. Volume 3. 2012. (Consultado el 15 de febrero de 2012.) Disponible en: https://www.hwa.gov.au/sites/uploads/ HW2025_V3_FinalReport20121109.pdf

6. Ministry of Health and Ontario Medical Association. Ontario population needs-based physician simulation model. Final report. October 2010. (Consultado el 15 de febrero de 2014.) Disponible en: (https://www. healthforceontario.ca/UserFiles/file/PolicymakersResearchers/needsbased-model-report-oct-2010-en.pdf

7. Gobierno de Chile. Estudio de brechas de oferta y demanda de médicos especialistas en Chile. Santiago de Chile: Subsecretaria de Redes Asistenciales, Departamento de Estudios de Recursos Humanos, 2010. Serie Cuaderno de Redes No. 31. (Consultado el 18 de febrero de 2012.) Disponible en: http://ciperchile.cl/wp-content/uploads/Estudio_subse_redes banco mundial.pdf

8. Barber Pérez P, González López-Valcárcel B. Oferta y necesidad de especialistas médicos en España, 2008-2015. Madrid: Ministerio de Sanidad y Consumo de España, 2009. (Consultado el 23 de febrero de 2012.) Disponible en: http://www.msssi.gob.es/profesionales/formacion/ necesidadEspecialistas/doc/13-NecesidadesMEspecialistas(2008-2025) pdf

9. Lázaro y De Mercado P, Blasco Bravo AJ, Lázaro y De Mercado I, et al. La reumatología en la Comunidad de Madrid: disponibilidad actual de reumatólogos y necesidades futuras, aplicando un modelo predictivo. Reumatol Clin. 2013:9:353-8.

10. Barber Pérez P, González López-Valcárcel B, Suárez Vega R. Oferta, demanda y necesidad de médicos especialistas en Brasil. Proyecciones a 2020. Sociedade Brasileira de Medicina de Família e Comunidade (SBMFC); 2012. (Consultado el 12 de mayo de 2014.) Disponible en: http://www.sbmfc.org.br/media/file/pdf/oferta\%20demanda\%20y\%20 necesidad\%20de\%20medicos\%20especialistas $\% 20$ brasil_patricia beatriz.pdf

11. Román AO, Feliú RO, Echavarría LA. Formación de médicos especialistas en el Sistema de Servicios de Salud de Chile. Su evolución en el período 2007-2010. Rev Med Chile 2011:139:762-9.

12. Birch S, Kephart G, Murphy GT, et al. Health human resources planning and the production of health: development of an extended analytical framework for needs-based health human resources planning. J Public Health Manag Pract. 2009;15(6 Suppl):S56-61.

13. Organización Panamericana de la Salud. Residencias médicas en América Latina. Serie: La renovación de la atención primaria de salud en las Américas N. ${ }^{\circ}$ 5. Washington, D.C.: OPS; 2011.

14. World Health Organization. Framework for action on interprofessional education and collaborative practice. Geneva, Switzerland: WHO; 2010.

15. General Medical Council. Our role. (Consultado el 20 de julio de 2014.) Disponible en: http://www.gmc-uk.org/about/role.asp

16. General Medical Council. The state of medical education on practice in the UK: 2013. (Consultado el 20 de julio de 2014.) Disponible en: http:// www.gmc-uk.org/publications/23435.asp

17. Conference of Posgraduate Medical Deans of the United Kingdom. COPMeD. About COPMeD. (Consultado el 20 de julio de 2014.) Disponible en: http://www.copmed.org.uk/about-us

18. Reines HD. Council on graduate medical education. (Consultado el 20 de julio de 2014.) Disponible en: http://www.iom.edu/ /media/Files/Activity\%20Files/Workforce/GMEGovFinance/2012-DEC-19/Reines.pdf

19. Simoens S, Hurts J. The supply of physician services in OCDE countries. 2006. Health Working Papers, No. 21. Paris: OCDE; 2006. (Consultado el 20 de julio de 2014.) Disponible en: http://www.oecd.org/els/health-systems/35987490.pdf

20. Accreditation Council for Graduate Medical Education (ACGME). About ACGME. (Consultado el 20 de julio de 2014.) Disponible en: http://www. acgme.org/acgmeweb/tabid/116/About

21. Echeverría Zuno S. La formación de médicos especialistas, una responsabilidad compartida. Cirugía y Cirujanos. 2008;76:449-50.

22. Secretaría de Salud (México). Acuerdo por el que se crea la Comisión Interinstitucional para la Formación de Recursos Humanos para la Salud. SSA-SEP. Diario Oficial de la Federación, 19 de octubre de 1983. (Consultado el 22 de julio de 2014.) Disponible en: http://www.cifrhs.salud. gob.mx/descargas/pdf/E34_marcolegal_normatividad_acuerdode_creacion.pdf

23. Secretaría de Salud (México). Norma Oficial Mexicana. NOM 001-SSA32012. Educación en salud para la organización y funcionamiento de residencias médicas. Diario Oficial de la Federación, 4 de abril de 2013. (Consultado el 22 de julio de 2014.). Disponible en: http://dof.gob.mx/ nota_detalle.php? codigo $=5284147 \&$ fecha $=04 / 01 / 2013$

24. Secretaría de Salud (México). Boletín de Información Estadística. Volumen 1. Recursos físicos, materiales y humanos. México: Secretaría de Salud, DGIS; 2011.

25. OECD. Health at a glance 2011. (Consultado el 10 de abril de 2014.) Disponible en: http://www.oecd.org/els/health-systems/49105858.pdf

26. OECD. Health at a glance 2013. (Consultado el 10 de abril de 2014.) Disponible en: http://www.oecd.org/els/health-systems/Health-at-aGlance-2013.pdf

27. McQuide P, Stevens J, Settle D. An overview of human resources for health $(\mathrm{HRH})$ projection models. Intrahealth International, 2008. Series: Technicalbrief 12. (Consultado el 20 de mayo de 2014.). Disponible en: http://www.intrahealth.org/files/media/an-overview-of-human-resourcesfor-health-hrh-projection-models/techbrief_12

28. González López-Valcárcel B, Barber Pérez P. Oferta y necesidad de médicos especialistas en España (2006-2030). Universidad de las Palmas de Gran Canaria; 2007. (Consultado el 20 de mayo de 2014.). Disponible en: http://www.msssi.gob.es/profesionales/formacion/ necesidadEspecialistas/doc/12-NecesidadesMEspecialis$\operatorname{tas}(2006-2030) . p d f$

29. Markham B, Birch S. Back to the future. A framework for estimating health-care human resource requirements. Can J Nurs Adm. 1997; 10:7-23.

30. Rizza RA, Vigersky RA, Rodbard HW, et al. A model to determine workforce needs for endocrinologists in the United States until 2020. J Clin Endocrinol Metab. 2003:88:1979-87.

31. Goodman DC, Fisher ES, Bubolz TA, et al. Benchmarking the US physician workforce. An alternative to needs-based or demand-based planning. JAMA. 1996;276:1811-7.

32. Ono $T$, Lafortune $G$, Schoenstein $M$. Health workforce planning in OECD countries: a review of 26 projection models from 18 countries. OECD Health Working Papers, No. 62. OECD Publishing; 2013. (Consultado el 20 de mayo de 2014.) Disponible en: http://www.oecd-ilibrary.org/docserver/download/5k44t787zcwb.pdf?expires $=1448858053$ \&id=id\&accname $=$ guest \& checksum $=71$ C4577BEEC2C055FC7C18C634C430C0

33. Hall TL. Why plan human resources for health? Geneva, Switzerland: WHO. (Consultado el 20 de mayo de 2014.) Disponible en: http://www. who.int/hrh/en/HRDJ_2 2 201.pdf 
34. World Bank. Indicators 2011-2015. Physicians (per 1,000 people). Disponible en: http://data.worldbank.org/indicator/SH.MED.PHYS.ZS

35. De Silva AP, Liyanage IK, De Silva ST, et al. Migration of Sri Lankan medical specialists. Hum Resour Health. 2013;11:21.

36. Hawthorne L. International medical migration: what is the future for Australia? Med J Aust. 2013;199(5 Suppl):S18-21.

37. Barber Pérez P, González López-Valcárcel B, Suárez Vega R. Oferta y necesidad de médicos especialistas en España. 2010-2025. Ministerio de Sanidad, Políticas Sociales e Igualdad de España. Diciembre 2011. (Consultado el 28 de mayo de 2014.) Disponible en: http://www.msssi. gob.es/profesionales/formacion/necesidadEspecialistas/doc/11-NecesidadesMEspecialistas(2010-2025).pdf

38. The Camden Group. Final Physician Needs assessment. St. Joseph Medical Center. Bellingham, Washington; 2010. (Consultado el 22 de mayo de 2014.) Disponible en: http://www.whatcomalliance.org/wp-content/uploads/2011/02/Camden1-28-11.pdf
39. Zevallos L, Pastor R, Moscoso B. Oferta y demanda de médicos especialistas en los establecimientos de salud del Ministerio de Salud: brechas a nivel nacional, por regiones y tipo de especialidad. Rev Peru Med Exp Salud Publica. 2011;28:177-85.

40. World Health Organization. Models and tools for health workforce planning and projections. Human Resources for Health Observer, 3. Geneva: WHO; 2010. (Consultado el 30 de mayo de 2014.) Disponible en: http:// apps.who.int/iris/bitstream/10665/44263/1/9789241599016 eng.pdf

41. Barenys M, Rota R, Moreno V, et al. Estudio prospectivo de un modelo clínico predictivo de dispepsia orgánica. Med Clin (Barc). 2003;121:766-71.

42. Curhan GC, Willett WC, Rimm EB, et al. Prospective study of beverage use and the risk of kidney stones. Am J Epidemiol. 1996;143:240-7.

43. Martín-Láez R, Ibáñez J, Lagares A, et al. ¿Era el actual superávit de neurocirujanos previsible en 2009? Análisis de la situación sobre la base de los datos del Informe de oferta y necesidad de especialistas médicos en España (2008-2025). Neurocirugía. 2012;23:250-8. 